\title{
Chaponost - Projet urbain du centre bourg, médiathèque
}

Catherine Coquidé

\section{(2) OpenEdition \\ Journals}

Édition électronique

URL : http://journals.openedition.org/adlfi/15365

ISSN : 2114-0502

Éditeur

Ministère de la culture

Référence électronique

Catherine Coquidé, "Chaponost - Projet urbain du centre bourg, médiathèque », ADLFI. Archéologie de la France - Informations [En ligne], Rhône-Alpes, mis en ligne le 26 août 2015, consulté le 03 mai 2019. URL : http://journals.openedition.org/adlfi/15365

Ce document a été généré automatiquement le 3 mai 2019.

(c) Ministère de la Culture et de la Communication, CNRS 


\title{
Chaponost - Projet urbain du centre bourg, médiathèque
}

\author{
Catherine Coquidé
}

Code INSEE de la commune : 69043

Lien Atlas (MCC) :

http://atlas.patrimoines.culture.fr/atlas/trunk/index.php?

ap_theme=DOM_2.01.02\&ap_bbox=4.710;45.689;4.781;45.729

1 Les résultats archéologiques du quatrième diagnostic mis en place à l'amont $d u$ réaménagement $d u$ centre-bourg et à l'emplacement de la future médiathèque auront livré une moisson d'information concernant à la fois les abords de l'enceinte castrale extra muros et la première urbanisation des lieux.

2 En dépit d'un cadre urbain extrêmement contraignant, réduisant de moitié la surface disponible par rapport à celle de la prescription, le sondage implanté perpendiculairement au mur d'enceinte a permis de mettre au jour le dernier état d'une section du fossé nord (profondeur minimum: 2,40 m) ainsi que la base d'un mur de contrescarpe. $\mathrm{Si}$, au plus bas, le profil et les comblements n'ont pu qu'être restitués à cause de forts ruissellements, le relevé des parties hautes montre, depuis le $\mathrm{xVI}^{\mathrm{e}} \mathrm{s}$. au moins, divers comblements limono-sableux homogènes avec plus ou moins de gravier alternant avec d'épais lits de petits blocs. La douve est alors large de plus de 10 mètres et se comble progressivement. Aucun dépotoir n'est observé à cet endroit, à l'exception de tout ou partie de deux carcasses de bovins adultes.

3 Le tracé du fossé, quoique réduit en largeur, est encore perceptible au XVIII ${ }^{\mathrm{e}} \mathrm{s}$., où il est finalement comblé puis remblayé. Les plans terriers et cadastraux montrent que les constructions récemment détruites suivent de peu, et occupent l'espace ainsi gagné. Dans l'intervalle, de nombreux travaux auront profondément modifié puis effacé les lignes historiques du centre-bourg. Les difficultés à restituer les niveaux de circulation par époque en découlent, notamment en ce qui concerne une pièce intégralement conservée côté ouest, sous la voirie actuelle. Un examen succinct y révèle au moins quatre grandes 
phases de construction, certaines sans doute en lien avec le bâti du XVIII ${ }^{\mathrm{e}} \mathbf{s}$., d'autres non datées, voire antérieures. À ce stade, la proximité de la seule porte médiévale conservée ne peut être ignorée, notamment concernant la base de l'épais mur oriental de la pièce. Ces considérations rendent plus que probable l'existence d'autres maçonneries et/ou d'espaces préservés en direction de l'ouest.

INDEX

Index géographique : Rhône-Alpes, Rhône (69), Chaponost

Keywords : Late Middle Ages, Modern period

Mots-clés : enceinte castrale, mur de contrescarpe, fossé, douve, maçonnerie

operation Opération préventive de diagnostic (OPD), 2013 - nºA : 2211248

Index chronologique : bas Moyen Âge, Temps Modernes

\section{AUTEURS}

\section{CATHERINE COQUIDÉ}

Inrap 